\title{
Medical DeVice Regulation AND THE PROPOSED THERAPEUTIC PRODUCTS BILl: DeVISING A NEW REGIME
}

\author{
Laura Hardcastle*
}

\begin{abstract}
Despite medical devices being integral to modern healthcare, New Zealand's regulation of them is decidedly limited, with repeated attempts at reform having been unsuccessful. With the Government now indicating that new therapeutic products legislation may be introduced before the end of the year, the article considers the case for change, including to promote patient safety, before analysing the draft Therapeutic Products Bill previously proposed by the Ministry of Health, and on which any new legislation is expected to be based. It concludes that, while the proposed Bill is a step in the right direction, introducing regulatory oversight where there is currently next to none, there is still significant work to be done. In particular, it identifies a need to clarify whether the regime is indeed to be principles-based and identifies further principles which might be considered for inclusion. It further proposes regulation of cosmetic products which operate similarly to medical devices to promote safety objectives, while finding a need for further analysis around the extent to which New Zealand approval processes should rely on overseas regulators. Finally, it argues that, in an area with such major repercussions for people's health, difficult decisions around how to develop a framework which balances safety with speed to market should not be left almost entirely to an as yet unknown regulator but, rather, more guidance from Parliament is needed.
\end{abstract}

\section{INTRODUCTION}

If nothing else, the year 2020 demonstrated the need for robust healthcare systems. Even now, New Zealand faces a daunting array of matters to address in the health sector, including the continued response to the COVID-19 pandemic (not to mention calls for an inquiry into how it has been handled 
thus far), ${ }^{1}$ a wholesale reorganisation of the sector ${ }^{2}$ following the New Zealand Health and Disability System Review, ${ }^{3}$ as well as confronting ongoing challenges to improve mental health across the country.

However, one area where reform has been underway for nearing 20 years without ever quite reaching completion is New Zealand's approach to therapeutic products generally and medical devices in particular. At present, medicines at least are subject to some regulation through the increasingly antiquated Medicines Act 1981, which requires that all medicines obtain ministerial approval (in practice granted after an assessment by Medsafe) before they can be sold, distributed or advertised. ${ }^{4}$ Once medicines are on the market, there are obligations to notify, and potentially seek approvals for, changes to the medicine and to report serious adverse effects. ${ }^{5}$ By contrast, medical device suppliers need merely to provide basic information on their product via an online database; there is no requirement that the regulator approve devices nor any formal obligation on suppliers to report problems. This is despite medical devices seeking to achieve the same therapeutic purposes as medicines (unlike medicines, medical devices simply act other than through metabolic, pharmacological or immunological means) ${ }^{6}$ and the potential harm unsafe devices can do, as demonstrated by recent scandals involving metal-on-metal hip implants and surgical mesh. ${ }^{7}$

In the early 2000s, attempts were made to regulate medical devices through the establishment of a combined Australia and New Zealand Therapeutic Goods Authority. However, when these efforts stalled, New Zealand was left to go it alone. In 2015 and 2016, papers were put to Cabinet proposing a new Therapeutic Products Bill which would, among other things, introduce regulation of medical devices. Progress was slow, and it was not until December 2018 that a draft Bill was ready for

* PhD student at Victoria University of Wellington and associate at Bell Gully. Many thanks to my supervisors, Prof Bill Atkin and Dr Mark Bennett.

1 Katarina Williams "Covid-19: Public health experts call for inquiry into New Zealand's coronavirus response" (22 October 2020) Stuff < $<$ www.stuff.co.nz $>$.

2 Andrew Little, Peeni Henare and Ayesha Verrall "Major reforms will make healthcare accessible for all NZers" (press release, 21 April 2021).

3 Health and Disability System Review Final Report (March 2020).

4 Medicines Act 1981, s 21.

5 Sections 24 and 41.

6 Sections $3-4$.

7 David Fisher "Half of decade-old metal hip implants defective" The New Zealand Herald (online ed, 22 August 2015) <www.nzherald.co.nz>; and Medsafe Adverse Event Reports Relating to Surgical Mesh Implants: Summary of data received by Medsafe (August 2018). 
consultation. Submissions on the draft Bill closed in April 2019 and were published in 2020. The Government has now indicated that a revised Bill will be introduced into Parliament later this year. ${ }^{8}$

This article considers whether the proposed Bill represents the right way forward for medical device regulation. First, I identify the wide range of competing principles which any future legislation will need to account for. Next, I consider how such principles apply in the context of the current regulatory regime, in order to determine whether change is in fact needed. Having found that it is, I consider the high-level features of the proposed Bill and whether they provide an appropriate framework for New Zealand's regulation of medical devices. Ultimately, this article concludes that, while the proposed Bill is a step in the right direction, there remains work to be done. This includes clarifying whether the regime is intended to be principles-based, expanding it to deal with certain cosmetic devices and to provide more structure around reliance on overseas approaches, and limiting the currently extensive powers afforded to the future regulator.

\section{PRINCIPLES FOR REGULATION}

Before analysing the specifics of either the current regime or the draft Therapeutic Products Bill, it is necessary to identify the principles which will necessarily underpin any medical device regulation. Ensuring safety is obviously a key concern; however, there are also other factors at play. In particular, the public (and industry) must have confidence in any regime, requiring some degree of transparency. Patient and professional groups will seek access to a range of devices in a timely manner to better aid with treatment, while industry participants will be concerned to reduce upfront costs associated with regulation. Any regime must also account for the realities of the New Zealand environment, including its small size, limited resources, and place within a highly globalised world, while also being flexible enough to cope with changing technologies.

We can therefore identify a wide range of principles that any regulatory regime will need to accommodate, including the following: ${ }^{9}$

(a) Safety: a regulatory regime for medical devices should promote patient safety, both by ensuring that devices are not actively harmful and that patients are not exposed to needless risk through use of ineffective devices.

(b) Information gathering/transparency: the regime should promote the provision of information to regulators and the public to encourage confidence.

(c) Realising the benefits of devices: the regime should enable patients to benefit from new devices as far as possible.

8 Thomas Coughlan "Government to introduce new law for vaccine after legal challenge" (19 May 2021) Stuff $<$ www.stuff.co.nz $>$.

9 These principles have been derived from a number of sources and underlying regulatory theories. However, a number of these principles can be observed in World Health Organisation Regional Office for the Eastern Mediterranean Regulation of medical devices: A step-by-step guide (2016). 
(d) Reducing barriers to market: the regime should facilitate products to get to market in order to encourage the continued production of new and better devices.

(e) Proportionate to risk: the regime should accommodate different levels of risk, both to ensure safety and to prevent unnecessary regulation and therefore cost.

(f) Ability to react: as well as accommodating individuals, the regime should be able to react to external events, including the rapid pace of technological change (and global pandemics).

(g) Accommodating globalisation: the regulatory regime should be designed to operate in a globalised world.

(h) New Zealand specific: the regime should be adapted to New Zealand's specific conditions. This may include:

(i) New Zealand's small population and limited resources;

(ii) the particular nature of New Zealand's medical device industry (which relies heavily on overseas imports and small to medium sized businesses) $;{ }^{10}$ and

(iii) New Zealand's unique constitutional and legal system, including the place of Te Tiriti o Waitangi and our reliance on our bespoke accident compensation scheme over personal injury negligence.

In some cases, these principles may prompt conflicting outcomes and will need to be balanced against each other to ensure a regime which is appropriate to New Zealand's particular situation.

\section{THE CASE FOR CHANGE}

Having identified various principles that regulation of medical devices needs to accommodate, I turn now to consider the existing regime and its deficiencies. Medical devices are defined by the Medicines Act to be any article intended for use in, on or for humans to achieve a therapeutic purpose, but which does not achieve its principal action through pharmacological, immunological or metabolic means. ${ }^{11}$ Under the current legislation, there is no express requirement that all medical devices be safe or effective, nor any obligation on suppliers of medical devices to demonstrate that they are safe before supplying them to the public. Some limited categories of devices are subject to particular requirements; for example, electrical medical devices must comply with the Electricity (Safety) Regulations 2010 while devices producing radiation are subject to the Radiation Safety Act 2016. However, there is no mechanism to ensure compliance before devices enter the market.

Instead, sponsors are merely required, within 30 working days of becoming the sponsor of a device, to provide certain information to the Web Assisted Notification of Devices (WAND) database. ${ }^{12}$ That required information is restricted to the risk classification of the device, the contact

10 Medical Technology Association of New Zealand Medical Technology: A Guide to Market Access in New Zealand (2010) at 3.

11 Medicines Act, s 3A.

12 Medicines (Database of Medical Devices) Regulations 2003, reg 6. 
details of the manufacturer and sponsor, and a product description, with a unique product identifier also required for particularly high-risk devices. ${ }^{13}$ No information around clinical testing or other safety information is required.

Once a device is on the market, there is no requirement for sponsors to report any untoward effects of their product $-\mathrm{s} 41$ of the Medicines Act imposes this requirement only in respect of medicines. The Minister of Health can prohibit importation, manufacture and supply of devices for a specified period, while the Director-General of Health can require suppliers of devices deemed unsafe to present evidence to the contrary or face being unable to supply their product. ${ }^{14}$ However, the former power may be exercised only once and for no more than 12 months, while the latter involves at least a 45day delay while sponsors are given the opportunity to show their device is safe.

Despite the clear gaps in the regime, particularly when compared with the medicines regime, it is difficult to conclusively say that our current laws regarding medical devices are inherently unsafe, at least when compared with the alternatives. While there have been well-documented instances where devices have proven to be unsafe or harmful (key examples being the use of metal-on-metal hip implants ${ }^{15}$ and surgical mesh), ${ }^{16}$ these devices were also supplied in overseas jurisdictions which do regulate medical devices. There are also arguments that, since most of New Zealand's medical devices come from overseas markets with regulation in place, such as the United States (US), New Zealand is already benefiting from that regulation, with purchasers such as PHARMAC and District Health Boards (DHBs) often requiring that suppliers show evidence of overseas approvals. ${ }^{17}$ Indeed, some submitters argued during the consultation on the draft Therapeutic Products Bill that the current system works to give "a clear framework for 'good actors' to comply in a safe and effective manner." 18 Reflecting the "reducing barriers to market" principle identified above, there are also widespread

13 Regulation 5.

14 Medicines Act, ss 37 and 38.

15 Phil Taylor "Hip patients: Why weren't we told?" The New Zealand Herald (online ed, 17 March 2012) $<$ www.nzherald.co.nz>.

16 Medsafe, above $\mathrm{n} 7$.

17 Jackson Allison "Submission to the Ministry of Health on the draft Therapeutic Products Bill" at [2]. The Pharmaceutical Management Agency or PHARMAC is in the process of entering into national contracts for hospital medical devices, while District Health Boards remain responsible for purchasing the remainder.

18 InterMed Medical Limited "Submission to the Ministry of Health on the draft Therapeutic Products Bill" at 1. 
concerns, from both industry participants and healthcare professional bodies, that any attempt at regulation will simply increase costs and cause delays in new treatments becoming available. ${ }^{19}$

There are, therefore, reasonable arguments for leaving the current system as it is. However, such arguments do not necessarily provide a complete picture, as indicated by the various principles identified above. While regulation was recognised as having its limitations, a large number of submitters on the draft Therapeutic Products Bill agreed that regulation would reduce some of the risks around devices, thus enhancing safety. ${ }^{20}$ Commentators have also suggested that greater regulatory scrutiny can have a positive impact, noting that the breast implants involved in the European scandal of the early 2010s had not been introduced in the US due to additional regulator caution. ${ }^{21}$ Indeed, the industry is not wholly opposed to regulation on grounds of safety either, with the Medical Technology Association of New Zealand (MTANZ) indicating its support for requirements that device suppliers "demonstrate that they meet an internationally-recognised standard for safety and performance."22

However, it is not only safety concerns which have prompted calls for change. In terms of the "accommodating globalisation" principle identified above, in proposing the Bill, officials raised concerns that New Zealand is out of step with many developed countries in failing to regulate medical devices. ${ }^{23}$ Indeed, recent efforts to promote regulation of devices internationally have seen pre-market regimes developed in such diverse countries as Canada, Australia, Brazil, Japan, Taiwan, South Africa, Costa Rica and Uganda. ${ }^{24}$ Officials further noted that "[d]eveloped countries also have formal and informal obligations in respect of global safety concerns (eg, counterfeit products)." 25 There were also thought to be practical advantages, including that regulation would allow Medsafe to disseminate

19 See for example Mylan New Zealand Ltd "Submission to the Ministry of Health on the draft Therapeutic Products Bill" at 3; and Royal Australasian College of Physicians "Submission to the Ministry of Health on the draft Therapeutic Products Bill" at 9.

20 See for example Health and Disability Commissioner "Submission on the draft Therapeutic Products Bill" at 2; and New Zealand Medical Association "Submission to the Ministry of Health on the draft Therapeutic Products Bill" at [6].

21 Gail A Van Norman "Drugs and Devices: Comparison of European and US Approval Processes" (2016) 1 JACC: Basic to Translational Science 399 at 408.

22 Medical Technology Association of New Zealand White Paper: Proposal for a New Zealand Regulatory Scheme for Medical Devices (March 2015) at 3.

23 Therapeutic Products Regulation Paper 1: Context and Overview (Office of the Minister of Health, 28 April 2016) at [2].

24 World Health Organization Global atlas of medical devices (2017); T Saidi and TS Douglas "Medical device regulation in South Africa: The Medicines and Related Substances Amendment Act 14 of 2015" (2018) 108 SAMJ 168; and Carmelo De Maria and others "Safe innovation: On medical device legislation in Europe and Africa" (2018) 7 Health Policy and Technology 156.

25 Therapeutic Products Regulation Paper 1: Context and Overview, above n 23, at [22]. 
better information regarding device safety to PHARMAC and DHBs, a potentially more effective use of resources given the particular roles those bodies play in New Zealand's specific regime. ${ }^{26}$ There is also presently a significant lack of information and transparency around the devices present in New Zealand and the risks associated with them; even WAND, with its limited information, is not accessible by the public. Further, while the lack of regulation allows devices to enter the market quickly, it also limits the ability for regulators to act to resolve issues as they arise, requiring them to rely heavily on industry cooperation and temporary prohibitions. ${ }^{27}$

There are, therefore, compelling reasons for change, not only in terms of potential safety gains, but also in terms of New Zealand's standing in a globalised world. The remainder of this article considers whether the draft Therapeutic Products Bill is the appropriate basis for such changes.

\section{THE DRAFT THERAPEUTIC PRODUCTS BILL}

\section{A Overview}

Having identified a need for new legislation, and considerations on which it should be based, I turn now to consider the draft Bill.

The draft Therapeutic Products Bill seeks to introduce a new regulatory regime for a range of therapeutic products, including medicines, medical devices, related products and potential future products which have yet to be developed (referred to as type-4 products). ${ }^{28}$ In so doing, it purports to adopt a devolved, principles-based approach, with the draft Bill establishing the principles and parameters of the regime, while the detail is to be contained in future regulations and, to a large extent, in regulator-made rules.

In terms of medical devices, the draft Bill would cover much the same range of products as are covered currently. However, it would introduce requirements that devices obtain approval before they can be imported or supplied. ${ }^{29}$ Specifically, before supplying a product, device sponsors would need to demonstrate that it was safe and effective, and that the device's likely benefits outweigh its likely risks, as well as that it complied with any further criteria imposed by the regulator. ${ }^{30}$ In making such

26 Ministry of Health Regulatory Impact Statement (11 November 2015) at [188].

27 See for example Medsafe's use of s 37 of the Medicines Act to prohibit point-of-care tests for COVID-19 which it has not approved. That prohibition expired on 22 April 2021 with no end to the pandemic in sight. In this case, a specific order prohibiting COVID-19 point-of-care tests was able to be made under specific COVID-19 response legislation: see the COVID-19 Public Health Response (Point-of-care Tests) Order 2021 issued under the COVID-19 Public Health Response Act 2020. However, reliance on specific legislation in this way is clearly not practical for the vast majority of medical devices.

28 Consultation draft Therapeutic Products Bill, cl 17.

29 Clause 51. This requirement also extends to medicines and type-4 products.

30 Clause 95. 
assessments, the draft Bill, and particularly the accompanying consultation materials, anticipate that the regulator will rely heavily on assessments undertaken by overseas bodies. ${ }^{31}$

In addition to products meeting certain standards, entities wishing to act as sponsors would also need to meet particular requirements, including that they be fit and proper persons. ${ }^{32}$ The draft Bill would also impose licensing requirements for entities involved in particular activities within the supply chain, including manufacturing and wholesaling. ${ }^{33}$

Consistent with the intention to regulate across a product's life, the draft Bill also includes an obligation on the regulator to ensure that it has a system in place to "continuously monitor the safety" of products including medical devices, as well as provision for regulations regarding reporting obligations. ${ }^{34}$ The regulator would also be granted the ability to make recall and safety orders, to take unsafe devices off the market, and to cancel product approvals and activity licences where requirements were no longer being complied with. ${ }^{35}$ The draft Bill also proposes to overhaul the enforcement regime contained in the Medicines Act, introducing the infringement notices which have become relatively common across multiple different regimes in recent years, ${ }^{36}$ and increasing the potential penalties up to a maximum of five years imprisonment plus a $\$ 200,000$ fine or a fine not exceeding $\$ 1,000,000 .{ }^{37}$ By contrast, the general penalty under the current Medicines Act is $\$ 500$, with an additional $\$ 50$ per day if the offence continues. ${ }^{38}$

The draft Bill therefore seeks to lay the foundation for more comprehensive regulation of medical devices, a long overdue change. But with the opportunities that introducing new legislation brings, it is worth asking whether what is currently proposed represents the right approach for New Zealand. The remainder of this article therefore considers key elements/themes of the draft Bill and whether the policy settings it proposes are appropriate. Specifically, I consider:

(a) the principles on which it is based;

(b) what products the draft Bill would cover through its definition of medical devices;

31 Clause 207; and Ministry of Health Therapeutic Products Regulatory Scheme: Consultation Document (December 2018) at [373]-[374].

32 Consultation draft Therapeutic Products Bill, cl 97.

33 Clause 53.

34 Clauses 118 and 160.

35 Clauses 108 and 162.

36 See for example the Fair Trading Act 1986, s 40D; the Building (Infringement Offences, Fees, and Forms) Regulations 2007; and the Resource Management (Infringement Offences) Regulations 1999.

37 Consultation draft Therapeutic Products Bill, cl 233.

38 Medicines Act, s 78. 
(c) the proposed reliance on overseas assessments; and

(d) the intended devolved, regulator-led approach.

\section{B A Principled Approach?}

A consistent feature of the Cabinet papers preceding the draft Bill was their indication that the Bill would be "principles-based". ${ }^{39}$ Principles-based regulation can take many forms, ${ }^{40}$ but at its heart involves regulation setting out principles to be met and interpreted rather than prescribing rules. Advocates suggest that, when properly implemented, it can be effective and durable, but recognise that it can generate unintended consequences such as firms acting conservatively to avoid being caught out by uncertain interpretations. ${ }^{41}$ Its popularity has risen and fallen over time, but it is particularly prominent in United Kingdom (UK) financial regulation. ${ }^{42}$

However, it is not clear that the regime proposed by the draft Bill is particularly principles-based, or will become so once fully implemented. The draft Bill starts by setting out a purpose and principles, as one might expect, with instructions that "[t]he Regulator and any other person exercising a power under this Act must be guided by the purpose of this Act and the ... principles". ${ }^{43}$ But this is simply an instruction for interpreting other more precise requirements of the Bill - it is not the type of openended command to achieve those principles commonly found in principles-based regulation and does not expand the reach of the more detailed rules.

Indeed, much of the proposed Bill comprises these precise requirements. For example, the criteria for sponsors are tightly defined, including through the definition of who amounts to a fit and proper person. ${ }^{44}$ Advertising requirements are also highly prescriptive, as are the requirements for licensees and responsible persons, while the powers of the regulator to issue certain orders are also relatively prescribed. This is not to say this is undesirable, rather that the description of the Bill in consultation documents should match reality.

39 Therapeutic Products Regulation Paper 2: Proposals for a Therapeutic Products Bill Proposal (Office of the Minister of Health, 28 April 2016) at [2.1]. See also Therapeutic Products Regulation Paper 1: Content and Overview, above n 23, at [35.1]; and Ministry of Health Therapeutic Products Regulatory Scheme: Consultation Document, above n 31, at iii.

40 See Julia Black "Forms and Paradoxes of Principles Based Regulation" (2008) 3(4) Capital Markets Law Journal 425 .

41 At 432 and 449.

42 See Julia Black "The Rise, Fall and Fate of Principles Based Regulation" in Kern Alexander and Niamh Moloney Law Reform and Financial Markets (online ed, Edward Elgar Publishing, 2010).

43 Consultation draft Therapeutic Products Bill, cl 4.

44 Clauses 47 and 97. 
The one area where the Bill may be principles-based is the criteria for product approval. Specifically, cl 95 of the draft Bill provides that the criteria for product approval are:

(a) the quality, safety, and efficacy or performance of the product for the purpose for which it is to be used are satisfactorily established;

(b) the likely benefits of the product outweigh the likely risks associated with it; and

(c) any other criteria specified by the regulator in rules.

While there is potentially a semantic argument as to whether these are outcomes or principles, the first two at least are high-level requirements which could be achieved in multiple different ways. However, cl 96 allows the regulator to impose product standards, including around quality, safety, efficacy or performance. As such, there is certainly capacity for (and likely an expectation on) the regulator to introduce more precise requirements that participants might meet in place of those higherlevel principles. In addition, the requirement in (c) above leaves room for doubt as to how the regime will be implemented by the regulator. The consultation document released by the Ministry of Health contemplates that the rules would be used to implement "Essential Principles" of the kind seen overseas. ${ }^{45}$ However, there is no specific requirement for the regulator to use that power in such a way.

So, is the regime principles-based? At present, the best answer seems to be that it could be, at least in part. However, if the regime stays in its currently heavily devolved form (see section E below for further comment on this), we likely will not know whether the regime does indeed contain principlesbased elements until the regulator has fully formulated the rules referenced in the Bill. This is unlikely to be for some time, with rules and regulations only likely to be developed in the two years after any new Bill passes. ${ }^{46}$

The bigger question is whether such a principles-based approach is desirable. As indicated above, principles-based regulation has its advantages, including providing regulated parties with flexibility in how they might comply and a greater capacity for regulation to move with the times. It can also assist in emphasising key issues for regulators, while avoiding strict drafting reduces the risk of loopholes. ${ }^{47}$ However, it can also lead to uncertainty. While regulators can issue guidance to alleviate such issues, this is not a complete answer. It may well be that the advantages of flexibility are lost through regulated parties behaving conservatively to avoid a perceived risk of liability, particularly amongst the smaller firms common in New Zealand that may have less capacity to challenge rulings against them. For regulators, this uncertainty may discourage rulings which are perceived as likely to be challenged, while investigative costs may be higher because rules cannot be directly and efficiently

45 Ministry of Health Therapeutic Products Regulatory Scheme: Consultation Document, above n 31, at [358].

46 At v.

47 Christopher Decker Goals-based and Rules-based Approaches to Regulation: BEIS Research Paper Number 8 (Department for Business, Energy and Industrial Strategy, May 2018) at 20. 
applied. ${ }^{48}$ Principles-based approaches often also place significant trust in regulated parties' expertise and judgement, leading to regulatory capture as regulators become increasingly reliant on that judgement to interpret regulations. ${ }^{49}$

There are also questions as to whether the flexibility inherent in a principles-based approach is a positive thing in a context where safety is so important. It is acknowledged that health and safety legislation (for example, the Health and Safety at Work Act 2015) is already highly principles-based; however, there have also been significant criticisms of that system, including around the reduction in prosecution rates and around the regulator's capacity to enforce the system. ${ }^{50}$ Indeed, commentators have noted the difficult task regulators face in ensuring they have the appropriate skills, mindset and judgement to oversee a principles-based regime without generating unpredictability, while also encouraging change in the thinking processes of regulated parties. ${ }^{51}$

Superficially then, a principles-based approach might offer some flexibility to regulated parties in reducing compliance costs and to regulators in adapting to external events. However, reliance on principles could equally well drive higher compliance costs due to uncertainties around what compliance entails and may be inappropriate for regulating a marketplace primarily comprising small firms, as seen in New Zealand's medical devices sector. There is also a need to ensure that the regulator charged with overseeing such a regime is up to the task and remains accountable. Ultimately, such a regime is likely to only be as effective as its regulator and the approach it takes, something which will not be known for some time.

If a principles-based approach is to be adopted, it will be essential to ensure the principles selected are appropriate and clear. As to the principles which are to guide decision-making under the draft Bill, these align with a number of the factors identified in section II above. Specifically, the principles recognise the importance of proportionality with risk but also seek to ensure that the benefits of devices are realised through "timely availability". ${ }^{52}$ The idea of alignment with international practices is consistent with accommodating globalisation, while also reducing barriers to market. The overall purpose in cl 3(a) of safeguarding community and public health through "ensuring acceptable safety, quality, and efficacy or performance of therapeutic products across their lifecycle" also appears consistent with my principle of safety identified above.

48 At 25 .

49 At 25 .

50 See for example Phil Pennington "WorkSafe investigators under pressure, lack training - report" (30 June 2020) Radio New Zealand <www.rnz.co.nz>.

51 Julia Black, Martyn Hopper and Christa Band "Making a success of Principles-based regulation" (2007) 1 Law Financial Mark Rev 191 at 199-200.

52 Consultation draft Therapeutic Products Bill, cl 4. 
There is some question as to how the requirement for efficacy will be interpreted. In a number of overseas jurisdictions, "efficacy" has merely required that a product achieve the results indicated by the manufacturer, leading to products gaining approval which might have little therapeutic benefit. ${ }^{53}$ This uncertainty led to one submitter proposing that devices be shown to have "clinical utility" (ie that the device will actually achieve a therapeutic outcome and benefit patients) before their approval. ${ }^{54}$ Indeed, such a principle is consistent with safety principles, since exposure to an ineffective device may have risks without the prospect of benefits.

The consultation on the Bill raised concerns that other objectives were being taken into account, with the consultation document identifying the support of New Zealand's trade and economic objectives as one such objective. Submitters were keen to ensure that such commercial objectives were properly insulated from issues of safety and efficacy and this seems a valid concern, ${ }^{55}$ while New Zealand's small size and import/export-driven economy mean trade will inevitably be a consideration, that trade would not be aided by allowing unsafe devices to enter the market. Another submitter proposed the addition of a principle that decisions be evidence-based. ${ }^{56}$ Care would have to be taken that such a principle was paired with other principles around ensuring safety and similar considerations in order to avoid a situation in which the regulator could not "prove" that a product was dangerous and, therefore, had to approve it. However, such a principle would again appear consistent with principles of safety as well as transparency. Consideration should be given to such principles in the next iteration of the draft Bill.

\section{The Bill's Coverage}

Under the draft Bill, the definition of medical device would remain much as it currently is, being a therapeutic product which achieves, or is likely to achieve, its primary intended action through means which are not immunological, pharmacological or metabolic. ${ }^{57}$ There is a small amendment to exclude from the definition devices comprising or derived from human or animal cells, such as particular in vitro diagnostic devices (IVDDs); these would be regulated via other means under the Bill. $^{58}$

53 Bernhard Lobmayr "An Assessment of the EU Approach to Medical Device Regulation against the Backdrop of the US System" (2010) 1 EJRR 137 at 139.

54 Royal College of Pathologists of Australasia "Submission to the Ministry of Health on the draft Therapeutic Products Bill" at 1.

55 New Zealand Medical Association, above n 20, at [2]; and Royal Australasian College of Surgeons "Submission to the Ministry of Health on the draft Therapeutic Products Bill" at 1.

56 Johnson \& Johnson Pty Ltd "Submission to the Ministry of Health on the draft Therapeutic Products Bill" at 7.

57 Consultation draft Therapeutic Products Bill, cl 21. Compare Medicines Act, s 3A.

58 It is, however, beyond the scope of this article to consider such devices further. 
The draft Bill would also amend the definition of "therapeutic purpose" from that currently found in the Medicines Act. Under the Medicines Act, therapeutic purpose is defined as: ${ }^{59}$

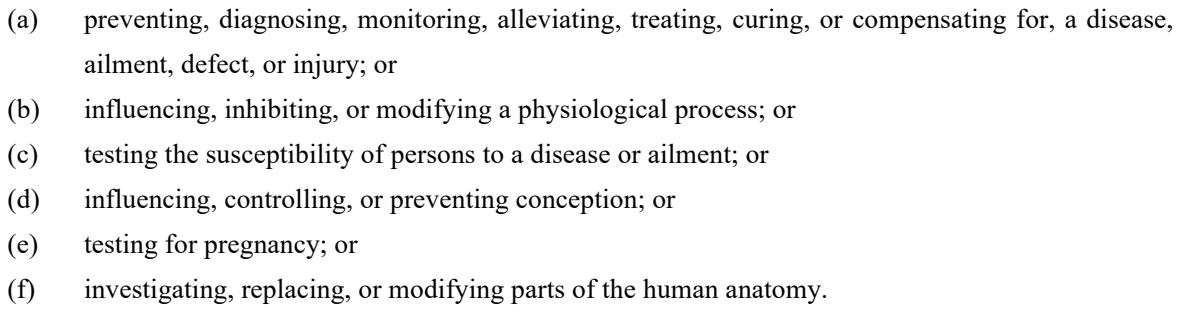

Under the proposed Bill, the above purposes would be supplemented with: ${ }^{60}$

(a) supporting and sustaining human life;

(b) disinfecting medical devices; and

(c) a purpose connected with a purpose referenced above.

Submissions on these definitions highlighted two key issues: whether the proposed Bill might inadvertently capture generic scientific equipment; and how the proposed Bill was intended to regulate products which, while similar to medical devices, are used for non-therapeutic (primarily cosmetic) purposes.

On the first of these, submitters were concerned that the proposed Bill might capture low risk, commonly used products. The Dental Council, for example, was unclear whether it would capture dental materials such as gold or amalgam. ${ }^{61}$ Others raised concerns as to whether the expanded definition would capture generic equipment such as laboratory equipment, reagents, tape measures or scales. $^{62}$

On its face the proposed Bill's addition of "purposes related to other purposes" does appear to capture such equipment. A test tube, for example, arguably assists with the purpose of whatever reaction takes place in it. If that reaction is part of a diagnostic test, then in theory it is a purpose connected to a therapeutic purpose. However, such an interpretation could be considered unduly literal. A test tube's purpose is, in fact, to hold chemical reagents. In doing so, it might assist with conducting a diagnostic test, but its purpose is not directly connected to the purpose of that test. Furthermore, even if such a provision were interpreted at the widest possible extreme, there would

59 Medicines Act, s 4.

60 Consultation draft Therapeutic Products Bill, cl 16.

61 Dental Council "Submission to the Ministry of Health on the draft Therapeutic Products Bill" at [89]-[91].

62 New Zealand Medical Association, above n 20, at [8]; Royal College of Pathologists of Australasia, above $n$ 54, at 2; and Canterbury District Health Board and West Coast District Health Board "Submission to the Ministry of Health on the draft Therapeutic Products Bill" at 1. 
still be the ability for the regulator to exempt certain classes of product from regulation. ${ }^{63} \mathrm{Such}$ issues therefore appear surmountable without amendments to the proposed Bill.

As to the second issue, this was specifically highlighted in the consultation document, which noted that the proposed Bill would not cover products with the features of medical devices but which are not intended for a therapeutic purpose, citing examples of "planar [sic] contact lenses, facial or other dermal fillers, and equipment used for cosmetic purposes that emits high-intensity electromagnetic radiation", ie IPL machines. ${ }^{64}$ However, as submissions on the draft Bill demonstrated, this is entirely too simplistic an approach. The New Zealand Association of Optometrists, for example, took exception to the Ministry's characterisation of plano contact lenses (ie lenses which do not refract), noting that while such products can be used for cosmetic purposes, optometrists do also utilise nonrefracting lenses and that many jurisdictions, including the US, Spain and the UK regulate all contact lenses as devices, given that all are capable of doing harm. ${ }^{65}$ Others noted that many of these "cosmetic devices" were in fact developed for medical purposes and could still be used for such, for example in reconstructive surgeries. ${ }^{66}$ As such, the line between cosmetic and therapeutic devices may not be distinct and manufacturers should not be able to avoid regulation simply by indicating their product should be used in the former and not the latter. Furthermore, a number of submitters, including the Nursing Council of New Zealand and Auckland Women's Health Council, highlighted the significant safety issues which can arise with such products, for example, dermal fillers are known to lead to blindness and stroke. ${ }^{67}$ Such submitters also noted the issues which have arisen with substandard breast implants overseas. ${ }^{68}$

Against the above arguments, a small minority of submissions, particularly those involved in the cosmetics industry, contended that such products should not be regulated as medical devices. Some preferred no regulation at all, maintaining that the issue was untrained beauticians rather than the

63 Consultation draft Therapeutic Products Bill, cl 114

64 Ministry of Health Therapeutic Products Regulatory Scheme: Consultation Document, above n 31, at [356].

65 New Zealand Association of Optometrists "Submission to the Ministry of Health on the draft Therapeutic Products Bill" at 5. See also Optometrists and Dispensing Opticians Board "Submission to the Ministry of Health on the draft Therapeutic Products Bill" at 2.

66 New Zealand Society of Cosmetic Medicine "Submission to the Ministry of Health on the draft Therapeutic Products Bill" at 4-5; New Zealand Dermatological Society Incorporated "Submission to the Ministry of Health on the draft Therapeutic Products Bill" at 1; Douglas Pharmaceuticals Limited "Submission to the Ministry of Health on the draft Therapeutic Products Bill" at 6; and Dentsply Sirona Proprietary Limited "Submission to the Ministry of Health on the draft Therapeutic Products Bill" at 4.

67 Nursing Council of New Zealand "Submission to the Ministry of Health on the draft Therapeutic Products Bill" at 5; and Auckland Women's Health Council "Submission to the Ministry of Health on the draft Therapeutic Products Bill" at 109-110.

68 Auckland Women's Health Council, above n 67, at 109-110. 
products, ${ }^{69}$ while others wanted separate regulation for devices used for cosmetic purposes, arguing that the alternative would simply increase compliance costs. ${ }^{70}$ However, it seems unrealistic to expect providers, whether trained healthcare providers or not, to assess the safety of all devices before they are used. Further, differential treatment would inevitably still incentivise manufacturers to have their devices classified as one rather than the other, yet do little to prevent end users from electing to use that product in different ways.

Regulating products using the same technology as medical devices, and which could be used for a therapeutic purpose (even if they are marketed for cosmetic rather than therapeutic purposes), would therefore be consistent with the principle of safety. There would also be capacity for the regulator to exempt particular classes of products if these were deemed sufficiently low risk.

\section{Reliance on Overseas Assessments}

Another key feature of the proposal is the degree of reliance it places on overseas approaches to, and assessments of, medical devices.

First, the consultation document makes clear that the intention behind the proposed Bill is to adopt the "regulatory model initially developed by the Global Harmonization Taskforce (GHTF) and further developed by its successor the International Medical Device Regulators Forum" (IMDRF). ${ }^{71}$ This model has multiple attractions, for example, proposing that devices be classified by risk, meeting the risk proportionality and reducing barriers to market principles identified above. Other elements of the approach, such as its advocacy for universal device identifiers, focus on safety objectives. Overall, aligning with a global approach satisfies principles of accommodating globalisation while also recognising the realities of New Zealand's position as a relatively small market.

However, such an approach is not entirely straightforward. In particular, while the GHTF/IMDRF have produced recommendations, there is not necessarily one "global model". There are certainly themes which exist across jurisdictions, including the use of risk classification and essential principles and, indeed, some jurisdictions are taking steps to harmonise these as far as possible (for example, Australia has taken steps to align its classifications of devices with Europe's, ${ }^{72}$ and is looking to do likewise with its essential principles) ${ }^{73}$ However, this is not universal; Canada's classification of some

69 Michelle du Preez "Submission to the Ministry of Health on the draft Therapeutic Products Bill" at 1.

70 Cosmetics New Zealand "Submission to the Ministry of Health on the draft Therapeutic Products Bill" at 2.

71 Ministry of Health Therapeutic Products Regulatory Scheme: Consultation Document, above n 31, at [353].

72 Therapeutic Goods Administration Delays to the commencement of certain medical device regulatory changes (23 July 2020) Australian Government - Department of Health <www.tga.gov.au>.

73 Therapeutic Goods Administration Consultation: Proposed changes to medical device Essential Principles for safety and performance (5 September 2019). 
devices (particularly IVDDs) differs significantly from that in Europe. ${ }^{74}$ Even Australia, while mirroring the European regime closely, chooses to reserve to its regulator the ability to make decisions on some high-risk devices where the Europeans rely entirely on third-party conformity assessment bodies. ${ }^{75}$ Post-market processes across all three countries are also quite distinct. Meanwhile some jurisdictions, such as the US, take a different approach entirely, focusing on the comparability of new devices with existing ones rather than on risk classifications. ${ }^{76}$

Therefore, it is difficult to contend for a single "global model" for device regulation and, indeed, one submitter on the proposed Bill suggested that no country had ever adopted the GHTF/IMDRF advice directly. ${ }^{77}$ New Zealand has also never been a member of either body, raising questions as to the appropriateness of simply adopting its documentation, while it was also argued that such international organisations produce documents "at glacial pace". ${ }^{78}$ Rather, most submitters suggested an approach of either aligning with Europe or Australia. ${ }^{79}$ While this would provide a more concrete example of how a regime might be applied, these remain only one set of options within the much wider range of approaches taken globally. New Zealand needs to consider its own particular circumstances and what works best in its context.

Then, once New Zealand has a regime in place, there is a question as to the degree to which it should be relying on assessments made by other regulators. On this, the proposed Bill says little, although cl 207 does provide that the regulator would be able to "rely on reports, assessments or decisions made by, or information received from, a recognised authority", with the regulator identifying recognised authorities taking into account criteria provided for in regulations. The draft Bill therefore leaves open the question of the degree to which the regulator would adopt overseas decisions versus making its own; however, the consultation document is clear that the regulator would not be undertaking conformity assessments for devices (being the essential assessments to determine whether devices conform with key requirements). Rather, scrutiny of applications would largely

74 Compare Health Canada Guidance Document: Guidance for the Risk-based Classification System for In Vitro Diagnostic Devices (IVDDs) (2016); and Regulation 2017/746 on in vitro diagnostic medical devices [2017] OJ L117/176, Annex VIII.

75 Therapeutic Goods Administration Overview of medical devices and IVD regulation (1 October 2020) Australian Government - Department of Health <www.tga.gov.au>.

76 MP Vekatesh and Divya Teja Bandla "Regulatory Assessment of Premarket Approval of Medical Devices in US and EU" (2017) 9 IJPCR 281 at 282.

77 Fisher \& Paykel Healthcare "Submission to the Ministry of Health on the draft Therapeutic Products Bill" at 7.

78 At 7.

79 See for example iNova Pharmaceuticals "Submission to the Ministry of Health on the draft Therapeutic Products Bill" at 7; and GlaxoSmithKline New Zealand "Submission to the Ministry of Health on the draft Therapeutic Products Bill" at 8 . 
involve the regulator assessing whether a device has the correct risk classification, that a recognised authority has performed the conformity assessment and that "certification of compliance is within its expiry date and contains the required information." 80 As MTANZ put it, such a limitation "does not allow pre-market controls at anything bar a verification level." 81

It may be that such an approach is necessary given New Zealand's small size and limited resources. While New Zealand regulators assess medicines applications, it is much harder to do so for medical devices given the diversity of technology involved. Indeed, many submitters, primarily industry participants, felt that reliance on overseas regulators was preferable, to reduce cost and increase practicality. ${ }^{82}$

However, if that is the approach New Zealand is to take, we need to be alive to the risks. In particular, as other submitters point out, issues have arisen with overseas approvals granted in respect of products such as surgical mesh, while the US $510(\mathrm{k})$ process has come under intensive scrutiny. ${ }^{83}$ In addition, the absence of a local regulator capable of undertaking essential assessments limits the capacity to take into account New Zealand specific conditions, with New Zealand's particular circumstances potentially warranting a more or less conservative approach to certain devices. ${ }^{84} \mathrm{New}$ Zealand's position in the globalised world may also be undermined if it is perceived to be "free-riding" on the back of other jurisdictions.

Such risks will need to be assessed against the cost and time implications of more fulsome regulation. New Zealand's relatively late adoption of comprehensive medical device regulation also means we have an advantage in being able to consider the variety of models already in existence and we should use this opportunity. Singapore, for example, has a nuanced approach where lower risk devices, which have been approved in multiple jurisdictions or which have been on the market for a prolonged period without instance, are eligible for immediate or expedited approval, while higher risk

80 Ministry of Health Therapeutic Products Regulatory Scheme: Consultation Document, above n 31, at [375].

81 Medical Technology Association of New Zealand "Submission to the Ministry of Health on the draft Therapeutic Products Bill" at 3.

82 See for example Medical Technology Association of New Zealand, above n 81, at 3; Association of New Zealand Audiology Incorporated "Submission to the Ministry of Health on the draft Therapeutic Products Bill" at 4; and AbbVie Limited "Submission to the Ministry of Health on the draft Therapeutic Products Bill" at 2 .

83 See for example Auckland Women's Health Council, above n 67, at 5; and New Zealand College of Midwives "Submission to the Ministry of Health on the draft Therapeutic Products Bill" at 7.

84 See for example the Ministry of Health's discussion around the reasons for maintaining a local regulator for medicines in Therapeutic Products Regulation Paper 1: Context and Overview, above n 23, at [26]. 
and novel devices are subject to more intensive scrutiny. ${ }^{85}$ New Zealand should consider exploring the diversity of models available globally before determining which is the right one for us.

\section{E A Devolved Approach?}

Since the first Cabinet papers were issued, the intention has been for any new therapeutic products regime to involve a "lean, principles-based Act containing the central regulatory requirements", but with the majority of the regime to be addressed in regulations and particularly regulator-made rules. ${ }^{86}$ Subsequent papers expanded on this, advocating for the Bill to provide "robust principles to guide regulatory practice", with the regulator then granted power to deliver on them. ${ }^{87}$

Devolving significant power to regulators was considered to have a number of advantages, including, as set out in the original regulatory impact statement: 88

(a) The Minister can avoid being involved in routine details and instead focus on major issues of public import and ensuring the regulator remains accountable.

(b) Decisions are made faster and more cost-effectively.

(c) There is a reduction in the "risk of perceived lack of independence".

(d) Such an approach would better comply "with public sector legislative and regulatory standards / requirements".

(e) The regime would be better able to keep up to date with technological change.

Such an approach was also said to be consistent with the Productivity Commission's ${ }^{89}$ advocacy for details of regimes to be limited to delegated legislation. ${ }^{90}$

These are valid arguments; New Zealand's ministers tend to have numerous and significant responsibilities across multiple portfolios and expecting them to understand the minutiae of every regime is unrealistic. It will also inevitably take longer and cost more for a regulator to develop a proposal, put it to the relevant Ministry, seek initial ministerial agreement followed by full Cabinet agreement to get regulations passed than it would if the regulator were able to simply make the change themselves. A faster pace of change would also assist in ensuring that any regulatory regime stays up

85 See Health Sciences Authority "Registration overview of medical devices" (10 October 2019) $<$ www.hsa.gov.sg>.

86 Therapeutic Products Regulation Paper 2: Proposals for a Therapeutic Products Bill, above n 39, at [2.1].

87 Ministry of Health Regulatory Impact Statement, above n 26, at [101]-[102].

88 At 22 .

89 The Productivity Commission was established under the New Zealand Productivity Commission Act 2010 to provide advice to the government on improving productivity to support the overall wellbeing of New Zealanders.

90 Ministry of Health Regulatory Impact Statement, above n 26, at [103]. 
to date. Thus, the Productivity Commission recommended that designers consider whether delegation can assist in future-proofing regulatory regimes, particularly those subject to technological and other changes. ${ }^{91}$

However, it is worth noting that, while the Productivity Commission did conclude that New Zealand's primary legislation is too detailed, it declined to identify the precise line to be drawn between what might be delegated to the Governor-General-in-Council and what might go to regulators. ${ }^{92}$ It also noted that, while some Crown entity regulators were in support of more delegation, other public sector bodies noted that requiring Orders in Council could impose greater discipline (for example, requiring regulatory impact analysis) and that poor regime design at the outset could result in the proliferation of delegated instruments. ${ }^{93}$ In addition, the Productivity Commission, in reaching its conclusions, provided significant analysis of overseas regimes' reliance on delegated legislation, noting opinions that New Zealand is "an outlier" in terms of the high level of detail provided in primary legislation. ${ }^{94}$ However, a review of overseas approaches to regulating medical devices shows that the comparable jurisdictions tend to rely on either primary legislation, such as the US Federal Food, Drug, and Cosmetic Act, ${ }^{95}$ or a combination of statute and regulations (such as Australia's Therapeutic Goods Act 1989 (Cth) and Therapeutic Goods (Medical Devices) Regulations 2002, and Canada's Food and Drugs Act RSC 1985 c F-27 and Medical Devices Regulations). ${ }^{96}$

There are also obvious disadvantages to regulating through regulator-made rules. As the Productivity Commission noted, a key consideration is the supposed lack of "democratic legitimacy" - the only accountability may be to the minister responsible for the regulator and, depending on the way the regulator is established, their abilities to influence its workings may be limited indeed. ${ }^{97}$ This concern is likely to be more significant the more integral to the regime a particular matter for regulation is or where issues are likely to be highly controversial and thus warranting political input. In addition, there is no "independent scrutiny" of such rules (for example, by the Parliamentary Counsel Office) to determine whether they are within scope and properly drafted. ${ }^{98}$ There are also

91 New Zealand Productivity Commission Regulatory institutions and practices (30 June 2014) at 233.

92 At 234 .

93 At 234

94 At 230 .

95 Federal Food, Drug, and Cosmetic Act 21 USC. The EU's Regulation 2017/745 on medical devices [2017] OJ L117/1 were also passed by the European Parliament and Council of the EU, although they technically constitute secondary legislation as primary EU law comprises treaties: European Commission "Types of EU law" <www.ec.europa.eu>; and European Commission "Adopting EU law" <www.ec.europa.eu>.

96 Medical Devices Regulations SOR/98-282.

97 New Zealand Productivity Commission, above n 89, at 232.

98 Geoffrey Palmer "Deficiencies in New Zealand Delegated Legislation" (1999) 30 VUWLR 1 at 21-22. 
more practical downsides, including potential lack of transparency, reduced abilities for affected parties to influence the process and greater uncertainty generated by more frequent rule changes.

There are therefore a number of advantages and disadvantages when it comes to delegating rulemaking power to the executive and specifically to regulators. However, the question is not so much whether it should be done at all, but rather whether the settings are right for it to be done in a particular case. Indeed, this approach is reflected in the current guidelines of the Legislation Design and Advisory Committee (LDAC) which note the need to balance competing considerations of ensuring the law is legitimate, certain and transparent, without broad and uncontrolled delegated powers, with ensuring it is durable and flexible. ${ }^{99}$ In particular, the guidelines advocate that matters of significant policy be addressed in primary legislation, suggesting whether policy is "significant" is to be judged based on whether the policy responds to the key problems/questions the legislation addresses, whether it is controversial and whether, without that policy, the overall implications of the primary legislation are unclear. ${ }^{100}$ By contrast, matters appropriate for secondary legislation include mechanical and technically complex matters, as well as those requiring flexibility or updating to deal with technological development and material which requires inputs from experts and key stakeholders. ${ }^{101}$

In this case, sch 3 of the draft Bill sets out numerous topics on which regulations can be made and rules issued. These are too extensive to address in detail, so I shall instead focus in on one key area: pre-market approvals and licences.

For pre-market approvals and licences, as noted above, the draft Bill sets out high-level requirements that products be safe and effective and that likely benefits outweigh likely risks. It also sets out requirements on sponsors, including what is required for them to be fit and proper persons. Regulations would then set out the period for which an approval is in force, criteria for selecting recognised authorities, obligations on sponsors and responsible persons holding licences/permits, as well as information to be included on licences/permits. ${ }^{102}$ There is also an ability for regulations to set requirements on persons in the supply chain for devices regarding how controlled activities are carried out, the storage, handling, transport of devices, and other matters. ${ }^{103}$ A reasonable portion of the regime would therefore be set out in primary or secondary legislation. However, it would be for the regulator to issue rules addressing important matters, such as: ${ }^{104}$

99 Legislation Design and Advisory Committee Legislation Guidelines: 2018 Edition (March 2018) at 64.

100 At $65-66$.

101 At 66 .

102 Consultation draft Therapeutic Products Bill, sch 3, cl 1.

103 Clause 55.

104 Schedule 3, $\mathrm{cl} 2$. 
(a) criteria for issuing product approvals over and above the very high-level requirements set out in the statute as well as the standards products can meet to show they comply with them;

(b) changes to products which are sufficiently major as to require them to obtain a new product approval;

(c) criteria for granting licences and permits; and

(d) procedural requirements for any applications.

The result is that much of the basis for determining whether products should be supplied in New Zealand and whether particular activities may be undertaken by applicants is left to the regulator to determine. Considering the LDAC guidance, some of these matters do indeed appear to go to the heart of the question in issue, specifically, what overarching criteria should a device need to meet to be supplied in New Zealand and to what degree should that assessment be completed by a New Zealand regulator as opposed to relying entirely on those conducted overseas. While the field of medical devices is undoubtedly technical, it is arguable that much of that technicality exists at the next layer down, that Parliament or the Executive Council could provide much greater direction for the scheme, without needing to set the specific international standards a product needs to comply with to show an essential principle is satisfied. Instead, the proposed Bill gives the regulator significant scope to make its own policy rather than going through elected individuals.

In addition, given its very nature as a regulator, it would then have responsibility for implementing the rules it makes, making decisions on whether products should be approved and whether licences/permits should be cancelled, requiring it to interpret its own rulings. Moreover, while the regulator would not make the final decision on prosecutions (it might choose to bring them, but it would be for a court to decide the outcome), it does have the ability to issue infringement notices for non-compliance. Thus, the regulator finds itself with legislative, executive and quasi-judicial powers. It should be added that these powers are not entirely unfettered. The regulator is required to consult before it makes rules, ${ }^{105}$ those rules are disallowable instruments eligible to be rejected under the Legislation Act $2012^{106}$ and of course any decision it makes is susceptible to judicial review by the courts. In addition, there are processes for certain regulator decisions, including decisions to refuse to approve a product or to cancel an approval to be reviewed by a review panel and potentially appealed to the District Court. ${ }^{107}$ However, consultation does not mean ideas will be accepted and getting a legislative instrument disallowed is notoriously difficult. In addition, the review right is not as comprehensive as it might be - the review panel, while directed to act independently, is appointed by the regulator and not all parties can seek review of all decisions. Concerned parties cannot, for example, seek review of a decision to approve a product or grant a permit.

105 Clause 267.

106 Clause 260.

107 Clauses 200-204 and sch 2. 
It is tempting to argue that such concerns, often linked back to the principle of separation of powers, are somewhat antiquated. For one, Medsafe already has significant flexibility in determining its approach to regulating medicines given that the existing provisions are so high-level. For another, the world is arguably moving increasingly towards a higher degree of power and flexibility for regulators, although there is of course a spectrum and each jurisdiction will be unique. One example of a degree of regulator flexibility cited in New Zealand is that of the Electricity Authority (the Authority) which is empowered under the Electricity Industry Act 2010 to make and amend the Electricity Industry Participation Code 2010 (the Code) in order to promote competition in, reliable supply by and efficient operation of the electricity industry. ${ }^{108}$ The Authority's Rulings Panel are also able to determine whether the Code has been breached. ${ }^{109}$

However, the lackadaisical approach under the existing Act is not an answer to what should be done moving forward. As for the Authority, there are some important distinctions. First, the consultation obligations on the Authority are more onerous - it is required to provide analyses of costs, benefits and alternative options (while not a full regulatory impact statement, it does at least get closer) along with its proposed Code amendments and is even required to have a specific consultation charter. ${ }^{110}$ Secondly, the Rulings Panel, while a part of the Authority, is separate from its Board with its members appointed by the Governor-General on the recommendation of the minister. ${ }^{11}$ Further, any decision of the Authority is appealable to the High Court on a question of law. ${ }^{12}$

Moreover, it is arguable that the Authority operates in a very different space to that which a new regulator under the draft Bill would occupy. The electricity industry is highly complex, not only in terms of the technology needed to keep the country running but also in terms of the multiple markets which operate to buy and sell electricity and the different considerations which might be at play. Medical devices may themselves be complex, but the industry around them is less so. Furthermore, for medical devices, lawmakers are principally trying to balance concerns around safety with ensuring they do not impose too many barriers to market, particularly since, as noted above, participants can range from large corporates to small traders selling imported products, not to mention the range of parties who might be captured by wholesaling, storage and transport requirements. It is, therefore, arguable that just because a particular approach may have been taken to electricity, it does not mean it should also apply to medical devices.

108 Electricity Industry Act 2010, s 32(1). See discussion in Mark Bennett and Joel Colón-Ríos "Public Participation in New Zealand's Regulatory Processes" in Susy Frankel and Deborah Ryder (eds) Recalibrating Behaviour: Smarter Regulation in a Global World (LexisNexis, Wellington, 2013) 181.

109 Electricity Industry Act, s 50.

110 Sections 49 and 41.

111 Section 24.

112 Section 64. 
For their part, only a few submitters on the draft Bill commented directly on the amount of power being afforded to the regulator, expressing concern around the level of detail being left to rulemaking. ${ }^{113}$ However, there was a general call for greater detail regarding the potential regime from a wide range of parties. ${ }^{114}$ Certainty was also a major concern: suppliers noted that they required significant certainty in order to operate since, in some cases, they might produce significant volumes of a product in a short space of time. ${ }^{115}$ As such, they argued that leaving too much detail to delegated legislation would generate too great a level of uncertainty and lead to information asymmetry as stakeholders would not know what was happening. ${ }^{116}$ Submitters also wanted to see greater consultation and engagement with the sector, either more generally or through use of working groups. ${ }^{117}$ Others expressed concern around the draft Bill's providing that rules might be valid even if made without proper consultation (which would seem to override conventional rights at public law). ${ }^{118}$

There are, therefore, arguments for and against increased delegation of rule-making powers and it will be important to get the balance right. While it is entirely appropriate for regulator-made rules to specify matters, such as technical standards products might meet to demonstrate compliance with key principles, at the very least, the primary legislation needs to be clear as to what those key principles, and the components, of the regime are. It should therefore set out the criteria and principles devices are to meet in full, not leave it for the regulator to add them at will, and should be clear if the intention is for suppliers to be subject to post-market obligations.

In addition, it is appropriate for the legislature to provide guidance as to the degree of reliance to be placed on overseas authorities, ie whether the regulator is expected to conduct its own assessments or simply tick a box to say someone else has. Such decisions have the potential to impact significantly on a number of the key principles identified above, including safety and accommodation of

113 Pharmacy Council "Submission to the Ministry of Health on the draft Therapeutic Products Bill" at 2 and 42; and New Zealand Self-Medication Industry "Submission to the Ministry of Health on the draft Therapeutic Products Bill" at 1.

114 See for example Nursing Council of New Zealand, above n 67, at 2; Canterbury District Health Board and West Coast District Health Board, above n 62, at 1; Johnson \& Johnson Pty Ltd, above n 56, at 6; and Mylan New Zealand Ltd, above n 19, at 3.

115 Allison, above n 17, at [52]; and Green Cross Health "Submission to the Ministry of Health on the draft Therapeutic Products Bill" at 1.

116 AbbVie Limited, above n 82, at 15.

117 Healthcare Logistics "Submission to the Ministry of Health on the draft Therapeutic Products Bill" at 27; Pfizer New Zealand Pty Ltd "Submission to the Ministry of Health on the draft Therapeutic Products Bill" at 1; Johnson \& Johnson Pty Ltd, above n 56, at 6; and Medical Technology Association of New Zealand, above n 81 , at 3 .

118 Consultation draft Therapeutic Products Bill, cl 267(3). 
globalisation (including whether New Zealand is playing its role as a responsible supplier of goods). At a more practical level, such decisions are likely to have repercussions for the level of funding required by the regulator; at present, Medsafe has only 60 staff, primarily involved in medicines assessment, pharmacovigilance and enforcement of the limited offences in the Medicines Act. ${ }^{119}$ The original Cabinet papers suggested that the new regulator would be of comparable size, with perhaps a modest increase in numbers. ${ }^{120}$ However, this would seem to be inadequate if the regulator is to make (and continually reassess) policy decisions around how the regime should operate and the degree to which it should rely on others' decisions. While greater reliance on overseas regimes would reduce the numbers of staff needed for device assessment, it would render decisions as to which overseas organisations to recognise increasingly vital. It is suggested that, if a high degree of reliance is proposed, it would be more appropriate to recognise such organisations through regulations, thus adding greater accountability to the process.

Finally, if significant power is to be devolved to the regulator, the regime's designers will need to ensure that it encourages effective consultation and that appellate mechanisms are adequate. This includes the introduction of an independent appeals body not appointed by the regulator (or else appeals to the courts) and an ability for parties other than manufacturers to engage in the process/appeal.

\section{CONCLUSION}

After almost 40 years, the Medicines Act 1981, and particularly its approach to medical devices, is ripe for change. However, it is crucial that the opportunity be taken to set up a new regime properly. As evidenced by the number of factors to be taken into account identified above, medical device regulation is a complex area with many competing imperatives; this only makes it more important to ensure an effective regime.

This article has identified fundamental questions around whether the regime is in fact principlesbased, as its drafters have suggested, and identified further principles for consideration if that is to be the approach taken. It has also proposed that the regime be extended to include cosmetic devices which can act similarly to medical devices to improve safety and to avoid products escaping scrutiny at the boundaries. It has further identified the significant reliance placed on a nebulous "global model" and regulators, and proposed a more careful review of available options, including more nuanced approaches such as that adopted by Singapore, to identify the best model for New Zealand. Finally, it has raised questions as to whether the level of devolution provided for in the regime is appropriate, and suggested that further guidance from Parliament or ministers should be sought, rather than entrusting policy matters with the potential for significant health consequences solely to the proposed regulator.

119 Medsafe "About Medsafe" (29 June 2020) <www.medsafe.govt.nz>.

120 Therapeutic Products Regulation Paper 1: Context and Overview, above n 23, at [33]. 